\title{
EDUKASI GIZI SEIMBANG MENGGUNAKAN APLIKASI WHATSAPP PADA SISWA MADRASAH ALIYAH DI KABUPATEN BOGOR
}

\section{MUKHLIDAH HANUN SIREGAR, RATU DIAH KOERNIAWATI}

Universitas Sultan Ageng Tirtayasa

e-mail: mukhlidah.hanunsiregar@gmail.com

\begin{abstract}
ABSTRAK
Remaja adalah kelompok daur hidup yang sangat memerlukan informasi tentang gizi seimbang. Hal ini dikarenakan, remaja mengalami masa transisi menuju dewasa yang perlu asupan gizi yang optimal agar terhindari dari masalah kesehatan. Kegiatan ini dilakukan untuk memberikan informasi gizi seimbang kepada siswa Madrasah Aliyah Daarul Fataa. Edukasi dilakukan menggunakan media sosial Whatsapp dengan mengumpulkan siswa dalam satu grup. Nilai ratarata skor pengetahuan pre dan post test yaitu 21,33 dan 49,33. Dan ditemukan bahwa skor pengetahuan pre dan post test berbeda secara signifikan (pvalue $=0,000$ ). Disimpulkan bahwa edukasi menggunakan Whatsapp efektif dalam memberikan informasi dan meningkatkan pengetahuan pada siswa Madrasah Aliyah. Kegiatan ini dapat dilakukan kembali dengan tetap mengupayakan inovasi dalam pemberian materi sehingga umpan balik peserta meningkat.
\end{abstract}

Kata Kunci: remaja, gizi seimbang, edukasi melalui whatsapp

\begin{abstract}
Adolescent is a life cycle that really needs information about balanced nutrition, because adolescents experience a transition period to adulthood who need optimal nutritional intake in order to avoid health problems. This activity was carried out to provide information on balanced nutrition for students at Madrasah Aliyah Daarul Fataa. Education was used Whatsapp, we put them together in one group. The result shown that mean of pre and post test scores were 21.33 and 49.33. And it was found a significant difference between pre and post test score ( $p$-value $=0.000)$. It was concluded that education using WhatsApp was effective to promote information and increase knowledge of Madrasah Aliyah students. This activity can be held with the innovation in delivering information so we get the increasing of participant feedback.
\end{abstract}

Keyword: adolescent, balanced nutrition, education with whatsapp

\section{PENDAHULUAN}

Remaja adalah masa transisi dalam daur kehidupan yang membutuhkan perhatian serius. WHO mendefinisikan remaja adalah mereka yang berusia 10-19 tahun. Pada masa ini terjadi pertumbuhan linear yang cepat, komposisi tubuh yang berubah, pematangan reproduksi, dan perkembangan psikososial. Pertumbuhan yang cepat biasanya diiringi oleh aktivitas fisiknya. Oleh karena itu, remaja membutuhkan asupan gizi yang optimal untuk memenuhi tuntutan pertumbuhan dan perkembangan (Sharlin \& Edelstein, 2011). Untuk menunjang asupan gizi yang optimal dibutuhkan pengetahuan yang baik terkait gizi seimbang.

Penelitian terdahulu menunjukkan bahwa pengetahuan remaja akan pedoman gizi seimbang kurang baik. Temuan Sari menunjukkan bahwa 78,2\% dari siswa SMAN 1 Pontianak memiliki pengetahuan tidak baik mengenai Pedoman Gizi Seimbang (Sari et al., 2020). Begitu juga pada penelitian Tepriandy yang menemukan bahwa 60\% siswa MAN di Medan memiliki pengetahuan gizi yang kurang baik (Tepriandy \& Rochadi, 2021). Sedangkan Damayanti menemukan hasil yang lebih rendah yaitu $47,18 \%$ siswi SMK di Surabaya memiliki pengetahuan gizi yang kurang baik (Damayanti, 2016).

Pengetahuan gizi remaja pada masa pandemi Covid-18 sangat diperlukan untuk membentuk pola konsumsi yang baik dalam tubuh remaja agar mencapai status gizi yang baik. Pengetahuan yang baik tentang gizi mungkin tidak memberikan dampak terhadap pola makan seseorang jika pengetahuan tersebut tidak dilandasi oleh keinginan dan motivasi untuk 
memperbaiki status gizi (Tepriandy \& Rochadi, 2021). Namun, semakin sering diberikan informasi, bisa memberikan motivasi yang kuat kepada individu untuk menerapkan pengetahuan gizi yang diperoleh dalam kehidupan sehari.

Indonesia telah mengalami pandemi covid-19 sejak Maret 2020. Kondisi ini menjadikan kita kesulitan untuk memberikan penyuluhan langsung kepada masyarakat. Adanya pembatasan sosial di masyarakat menjadikan kita harus melakukan inovasi dalam pengabdian masyarakat. Media sosial menjadi salah satu media yang digunakan masyarakat untuk berkomunikasi dengan lainnya. Di antara media sosial yang digunakan seperti Whatsapp, Telegram, Instagram, dan Facebook. Selain itu, media yang melayani ruang rapat online juga banyak digunakan untuk memberikan penyuluhan kepada masyarakat.

Kuliah Whatsapp adalah program tanya jawab lewat group di aplikasi Whatsapp. Fitur Whatsapp ini banyak digunakan karena memiliki kelebihan yaitu dapat mengumpulkan 250 orang dalam satu grup. Selain itu, kita dapat membagikan gambar, video, audio maupun pdf dan microsoft office lainnya. Penggunaan Whatsapp dalam proses edukasi juga memberikan efektivitas yang baik seperti disampaikan dalam penelitian Gon dan Rawekar (Gon \& Rawekar, 2017). Selain itu, siswa SMA/sederajat juga sudah mengakses Whatsapp untuk keperluan sehari-hari.

Berdasarkan uraian di atas, maka dilakukan edukasi online melalui Whatsapp tentang pedoman gizi seimbang pada siswa Madrasah Aliyah Daarul Fataa di Kecamatan Bojonggede, Kabupaten Bogor.

\section{METODE PELAKSANAAN KEGIATAN}

Metode pelaksanaan kegiatan pengabdian kepada masyarakat yang telah dilakukan yaitu memberikan edukasi melalui Kuliah Whatsapp (KulWap) dengan Tema Edukasi Gizi Seimbang. KulWap dilakukan dengan memberikan materi terkait pengenalan istilah gizi di Indonesia, definisi gizi seimbang, 4 pilar gizi seimbang, 10 pesan gizi seimbang, isi piringku dan contoh menu makanan yang dapat dianjurkan dikonsumsi oleh remaja.

Kegiatan ini dilaksanakan dalam satu periode waktu yaitu pada Rabu, 2 Desember 2020. Rangkaian pelaksanaan kegiatan pada saat KulWap yaitu pembukaan yang dilakukan oleh moderator, perkenalan narasumber, pengisian pre-test, penyampaian materi berupa slide dalam bentuk pdf, diskusi dan tanya jawab, pengisian post-test, dan kesimpulan serta penutup dari moderator. Sasaran dari kegiatan KulWap ini adalah siswa kelas 10-12 Madrasah Aliyah Daarul Fataa Kecamatan Bojonggede Kabupaten Bogor.

Untuk mengetahui apakah ada peningkatan pengetahuan peserta selama mengikuti kegiatan ini maka dilakukan analisis data hasil pre-test dan post-test dengan analisis univariat dan bivariat dengan t-test berpasangan.

\section{HASIL DAN PEMBAHASAN}

Kegiatan telah diikuti dengan antusias oleh peserta KulWap. Berikut merupakan hasil dan pembahasan kegiatan yang telah dilaksanakan:

\section{Hasil}

Tabel 1. Distribusi pengetahuan "gizi seimbang" siswa MA Daarul Fataa ( $=30)$

\begin{tabular}{cccc}
\hline Penilaian & Rata-rata & $\begin{array}{c}\text { Nilai Min- } \\
\text { Max }\end{array}$ & Standar Deviasi \\
\hline Pre-test & 21,33 & $0-60$ & 17,37 \\
Post-test & 49,33 & $0-80$ & 25,04 \\
\hline
\end{tabular}

Tabel 1 menunjukkan bahwa rata-rata skor pengetahuan peserta sebelum diberikan Kulwap 21,33 dan meningkat menjadi 49,33 setelah diberikan Kulwap. Nilai tertinggi peserta sebelum diberikan Kulwap sebesar 60 dan meningkat menjadi 80 setelah diberikan Kulwap. Dapat diasumsi ada peningkatan pengetahuan peserta sebelum dan setelah diberikan KulWap 
terkait gizi seimbang. Untuk membuktikan hal tersebut dilakukan uji hipótesis t-test berpasangan dengan hasil sebagai berikut:

Tabel 2. Analisis bivariat pengetahuan pre dan post KulWap

\begin{tabular}{cccc}
\hline Penilaian & Rata-rata & 95\% CI & Pvalue \\
\hline Pre-test & 21,33 & $-39,02-(-16,97)$ & 0,000 \\
Post-test & 49,33 & & \\
\hline
\end{tabular}

Berdasarkan Tabel 2 terbukti bahwa ada perbedaan skor pengetahuan siswa MA Daarul Fataa sebelum dan sesudah diberikan KulWap terkait gizi seimbang.

\section{Pembahasan}

Remaja usia 15-18 tahun merupakan kelompok usia yang mengalami masa transisi. Perbaikan pengetahuan terkait gizi seimbang pada masa ini diharapkan dapat mencegah dari penyakit degeneratif di saat usia dewasa. Kegiatan ini telah dilaksanakan dengan baik. Beberapa peserta sangat antusias berdiskusi terkait menú gizi seimbang yang baik untuk mencegah obesitas.

Aplikasi Whatsapp merupakan salah satu media yang banyak digunakan oleh masyarakat Indonesia. Pada masa pandemi Covid-19 ini, Whatsapp menjadi salah satu media pembelajaran yang digunakan di sekolah, mengingat pada saat ini fitur dalam Whatsapp pun lebih mudah. Kita dapat mengirimkan gambar, video, audio, serta materi berbentuk PDF ataupun Microsoft office lainnya. Selain itu, metode ini cukup efektif digunakan pada masa Covid-19 ini untuk meminimalisir adanya kerumunan. Kegiatan yang sama telah terbukti memberikan efek yang baik terhadap pengetahuan peserta kulwap (Febrianti et al., 2020; Ratnaeni et al., 2021).

Pelaksanaan kulwap dalam grup juga mempunyai kelebihan yaitu memungkinkan peserta bertukar pesan dengan jumlah tak terbatas, dan pesan yang sudah dikirimkan ke grup dapat tersimpan secara otomatis sehingga dapat dibuka kembali kapan saja. Selain itu, jumlah dalam sebuah grup juga bisa mencapai 250 orang sehingga kita dapat menyampaikan informasi kepada banyak orang secara bersamaan (Gon \& Rawekar, 2017).

Akan tetapi tetap perlu diperhatikan kelemahan edukasi menggunakan Whatsapp ini, diantaranya yaitu kurangnya jangkauan peserta penyuluhan. Pada kegiatan ini, semua siswa kelas 10-12 di MA Daarul Fataa diberikan materi terkait gizi seimbang, hanya saja yang memberikan umpan balik pada pre dan post test hanya 30 orang dari 82 jumlah siswa yang hadir di grup saat kulwap dilaksanakan. Ini tentu menjadi perhatian bagi pelaksana kegiatan berikutnya untuk melakukan inovasi agar semua peserta dapat memberikan umpan balik saat melaksanakan kulwap.

Usia peserta merupakan masa yang sangat sensitif untuk membahas terkait apa yang dikonsumsi untuk memperoleh status gizi yang normal. Hasil penelitian Hyun menunjukkan bahwa siswa SMA/sederajat yang mempunyai pengetahuan gizi yang baik berkorelasi dengan perhatian terhadap konsumsi harian, walaupun dalam pelaksanaannya masih tergantung pada ketersediaan pangan di keluarga (Damayanti, 2016; Hyun et al., 2017). Oleh karena itu perlu untuk terus memberikan pengetahuan gizi kepada remaja untuk menjaga asupan harian tidak berlebih dan terhindar dari masalah kesehatan di masa yang akan datang.

Selain itu, remaja sangat rentan memperoleh informasi dari berbagai media. Informasi yang salah seperti metode diet ekstrim atau promosi terkait makanan fast-food tertentu dapat memberikan pengaruh terhadap referensi makanan remaja. Dan media sosial menjadi salah satu media yang dipakai remaja untuk memperoleh informasi (Tepriandy \& Rochadi, 2021). Oleh karena itu, media sosial dapat digunakan sebagai wadah untuk melakukan edukasi kepada remaja.

Hasil analisis pada item pertanyaan yang disampaikan sebagai evaluasi, sebagian besar peserta belum familiar dengan istilah "pedoman gizi seimbang". Peserta masih mengingat 
slogan 4 sehat 5 sempurna sebagai slogan gizi dalam pengaturan konsumsi harian. Hal sama juga ditemukan pada penelitian Sari yang menunjukkan bahwa masih rendahnya pengetahuan siswa SMAN terkait pedoman gizi seimbang (Sari et al., 2020). Padahal jika dilihat sejarah, Kemenkes telah mengganti slogan ini pada tahun 2014, dan sudah tujuh tahun berlalu. Hal ini tentu harus menjadi perhatian bersama untuk terus mensosialisasikan slogan "pedoman gizi seimbang" kepada semua kalangan masyarakat.

\section{KESIMPULAN}

Kesimpulan dari kegiatan ini adalah ditemukan peningkatan pengetahuan siswa MA Daarul Fataa tentang gizi seimbang melalui edukasi online menggunakan Whatsapp. Kegiatan yang sama juga dapat dilakukan oleh praktisi lainnya, dengan tetap mengupayakan keterlibatan semua peserta dalam memberikan umpan balik kegiatan. Upaya ini harus dilakukan terus menerus untuk menyebarluaskan slogan gizi seimbang kepada seluruh kalangan masyarakat.

\section{DAFTAR PUSTAKA}

Damayanti, A. (2016). Hubungan Citra Tubuh, Aktivitas Fisik, Dan Pengetahuan Gizi Seimbang Dengan Status Gizi Remaja Putri. In Skripsi. Universitas Airlangga.

Febrianti, T., Sabilla, M., Ariasih, R. R. A., Mustakim, \& Efendi, R. (2020). Edukasi Tentang Diabetes Melitus dalam Mempersiapkan Hidup Berkualitas di Masa Usia Lanjut Melalui Kulwap (Kuliah Whatsapp). Jurnal Pengabdian Masyarakat Indonesia Maju, 01(03), 68-72. https://doi.org/10.33221/jpmim.v1i03.819

Gon, S., \& Rawekar, A. (2017). Effectivity of E-Learning through Whatsapp as a Teaching Learning Tool. MVP Journal of Medical Sciences, 4(1), 19-25. https://doi.org/10.18311/mvpjms/0/v0/i0/8454

Hyun, H., Lee, H., Ro, Y., Gray, H. L., \& Song, K. (2017). Body image, weight management behavior, nutritional knowledge and dietary habits in high school boys in Korea and China. Asia Pacific Journal of Clinical Nutrition, 26(5), 923-930. https://doi.org/10.6133/apjen.122016.05

Ratnaeni, Bukhari, A., Hidayanty, H., Astuti, N., Daud, Bahar, B., \& Mastuti, N. (2021). Pengaruh Edukasi Media Whatsapp Tentang Gizi Laktasi, Involusi Uteri, dan Lochea Terhadap Pengetahuan, Sikap Dan Perilaku Ibu Nifas. Oksitosin: Jurnal Ilmiah Kebidanan, 8(1), 20-33.

Sari, E., Rafiony, A., \& Rapina. (2020). Pengetahuan Tentang Pedoman Gizi Seimbang Dan Pola Makan Siswa Sman 1 Pontianak. Pontianak Nutrition Journal (PNJ), 3(1), 1-5. https://doi.org/10.30602/pnj.v3i1.623

Sharlin, J., \& Edelstein. (2011). Essentials of Life Cycle Nutrition. Jones and Bartlett Publisher.

Tepriandy, S., \& Rochadi, R. K. (2021). Hubungan pengetahuan dan sikap dengan status gizi siswa MAN Medan pada masa pandemi COVID-19. TROPHICO: Tropical Public Health Journal, 1(1), 43-49. 